\title{
The Role of Marketing Knowledge Management in Achieving Competitive Advantage A Field Study on Amman's Hotels
}

\author{
Abdullah Hersh $^{1} \&$ Khalil Aladwan ${ }^{1}$ \\ ${ }^{1}$ Al-Balqa Applied University, Jordan \\ Correspondence: Abdullah Hersh, Al-Balqa Applied University, Jordan. E-mail: Abdullah.hersh@gmail.com
}

Received: December 25, 2013 Accepted: February 18, 2014 Online Published: May 21, 2014

doi:10.5539/ijms.v6n3p163 URL: http://dx.doi.org/10.5539/ijms.v6n3p163

\begin{abstract}
Knowledge management became one of the most important and modern topics in the present day, and it also became a basis which we depend upon it in concentration efforts of multilateral perspectives and different interests, especially those who work in the marketing management, but can marketing knowledge management achieve competitive advantage? This study aimed dignifying the role of marketing knowledge management (MKM) and its effect in achieving the competitive advantage in Amman hotels. To achieve the purpose of study a questionnaire was prepared by the researchers and delivered to the administration employees in the working hotels in Amman that are classified (three, four and five stars). The statistical procedure (SPSS) was used to analyze the data of the study. The findings of this study are there is a significant statistical effect for the knowledge in the markets for the needs and desires of the customers and for available marketing chances in achieving the competitive advantage according to the significance and the responding, and there is a significance statistical effect for the knowledge in the markets, for the needs and desires of the customers and for the available marketing chances to achieve the competitive advantage according to the responding.
\end{abstract}

Keywords: marketing knowledge management, competitive advantage, significance, responding

\section{Introduction}

The twenty first century has witnessed lots of challenges that have been facing the business organization, such as the rapid change in information technology and telecommunications to such small and big organization to be completive to cape up with the developments and to face the challenge of competition in order to say in the market. For this reason the notion of marketing knowledge management is formed. a number of scientists of administration have come with their philosophy about the importance of marketing knowledge as a basic source for creating a competitive advantage for the business organizations without differentiating between the its business domains (Akaah et al., 1988) implied that marketing knowledge is an essential substance that play a significant role in the discipline of marketing work, and it is an objective pillar in formulating successful marketing plans which based on the wisdom of mind to measure the market variables, so knowledge management has become one of the most important activities for any business organization want to continue and success in the markets and seeks to discover new ways which more effective than those used by competitors (Forearm \& Harem, 2004).

Marketing knowledge and activating the marketing performance in general. Therefore those business organization, in general and the hotels institutions, in particular should enhance their competitive situation through enhance their competitive situations through managing its marketing knowledge represented by the knowledge ok markets, completion, customers, needs and desires and the knowledge of the available marketing chances in order to cape with whets is going on of the developments in the markets to build up a modern vision originated from the accurate knowledge of the real situations in the markets, so getting that knowledge besides the available knowledge balance will give them the ability to develop relationships and access to its objectives (Almagribi, 2002), therefore, the importance of having a deep marketing knowledge for the organization be comes true through its outputs measured its inputs in addition, the organization in managing their marketing knowledge tend to focus on developing the organization marketing performance to gain competitive advantage. The aim of this study is the same of the business origination to focus on the administration the marketing 
knowledge for clarifying its roles in achieving the competitive advantage of the working hotels in Amman city as the sample of the study.

\section{Problem and Questions of the Study}

The problem of the study is answer the main question of the study which is what is the role of marketing knowledge management in achieving the competitive advantage for the working hotels in Amman a part of the gap by answering the following question:

1) What is the role of the market knowledge in achieving the competitive advantage for the working hotels in Amman?

2) What is the role of the marketing knowledge of the customer's needs and desires in achieving quality of the working hotels in Amman?

3) What is the role of marketing knowledge in the market chances in achieving the competitive advantage for the working hotels in Amman?

4) What is the role of marketing knowledge in the surrounding competitive in achieving the competitive advantage for the working hotels in Amman?

\section{The Main Objective}

Shedding light on the role of (MKM) in achieving the common competitive advantage in the hotels of Amman, there are several sub-goals include:

1) Emphasis on the role of marketing knowledge management in general and what MKM contained in the knowledge of markets, customers needs and desires, and find out the available market opportunities and the surrounding competition in improving and enhancing the competitive advantage in operating hotels in Amman.

2) The study Aims to measure and examine the current situation of the knowledge management in the service sector, especially in the hotels operating in Amman and how it could be developed to achieve the goals of development, growth and competition in the hotel sector.

3) Identify the nature of the relationship between marketing knowledge management and competitive advantage in operating hotels in Amman, from the viewpoint of managers and employees.

4) Present Recommendations to strengthen the role of knowledge management in its various forms in development and promotion of competitive advantage in operating hotels in Amman.

\section{The Importance of Study}

Economy, distinguishing and stability in the markets are based basically on marketing knowledge as main gear for economic growth through the availability of information technology, communication, marketing studies in addition to the availability of qualified and highly-skilled human resources.

The service sector in general and the hotels service sector, in particular are considered the main vein and the beating heart for the Jordanian economy.

Therefore, the significance of this study is originated from the important of the sector.

In addition, it is important to point to the information and knowledge in all its shapes in different sectors and particularly in the service sector on which the whole world and Jordan appending to back up the national economy.

This study also is significant because of the lack of studies that dealt with the topic of this study at the level of the Jordanian capital Amman. 


\section{Study Model}

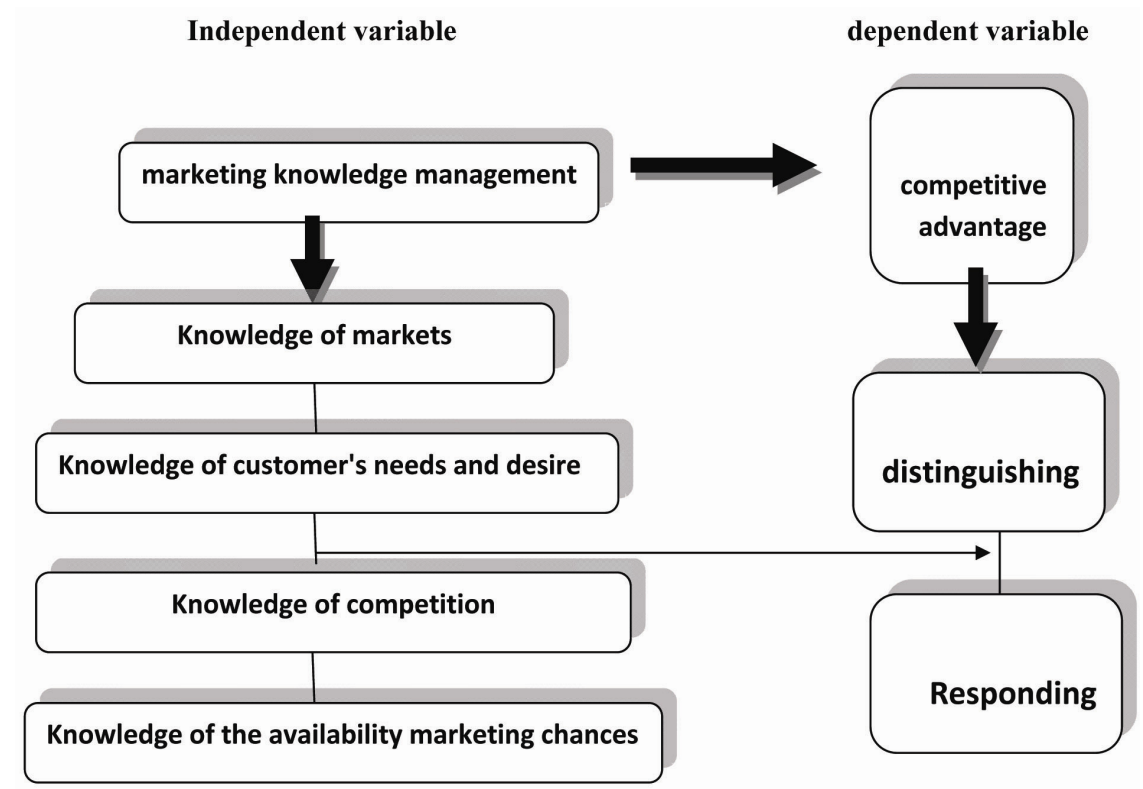

Figure 1. Study model

\section{Study Hypotheses}

\subsection{The Main Hypotheses}

There is no significant statistical effect for the marketing knowledge management (knowledge of markets, Knowledge of customer's needs and desire, Knowledge of competition, Knowledge of the availability and marketing chances) to achieve the competitive advantage for the working hotels in Amman according to (distinguishing, responding) at the statistical reference level $(0.05 \geq \alpha)$.

\subsubsection{Sub-Hypothesis Is Originated}

HO1: There is no significant statistical effect for the knowledge in achieving a competitive advantage from Distinguish side at the statistical reference level $(0.05 \geq \alpha)$.

HO2: There is no significant statistical effect for the knowledge of the customer's needs and desires in achieving a competitive advantage from Distinguish side at the statistical reference level $(0.05 \geq \alpha)$.

HO3: There is no significant statistical effect for the knowledge of competition in achieving the competitive advantage from Distinguish side at the statistical reference level $(0.05 \geq \alpha)$.

HO4: There is no significant statistical effect for the knowledge of the availability marketing opportunities in achieving the competitive advantage from Distinguish side at the statistical reference level $(0.05 \geq \alpha)$.

HO5: There is no significant statistical effect for the knowledge in achieving a competitive advantage from responding side at the statistical reference level $(0.05 \geq \alpha)$.

HO6: There is no significant statistical effect for the knowledge of the customer's needs and desires in achieving a competitive advantage responding side at the statistical reference level $(0.05 \geq \alpha)$.

HO7: There is no significant statistical effect for the knowledge of competition in achieving the competitive advantage from responding side at the statistical reference level $(0.05 \geq \alpha)$.

HO8: There is no significant statistical effect for the knowledge of the availability marketing opportunities in achieving the competitive advantage from responding side at the statistical reference level $(0.05 \geq \alpha)$.

\section{Methodology and Procedure of the Study}

\subsection{Method of the Study}

The descriptive analytical method is used in data collecting. 
The related literature was reviewed and a questionnaire is prepared by the searchers for colleting and measuring the data.

\subsection{Procedure of the Study and the Sample}

The population of the study includes the administration employees in the working hotels in Amman which are classified (three, four and five stars Hotels).

The sample of the study includes the working administration employees hotels in Amman from the medium and high administration levels.

\subsection{Resources for Data Colleting}

\subsubsection{Secondary Data Resources}

The theoretical studies related to the topic of study from the available books, related studies and data from the internet.

\subsubsection{The Primary Data Resources}

The main data collected by the question of the questionnaire that was prepared to meet the purposes of the study.

\subsection{Measuring the Variables}

The role of marketing knowledge the competitive advantage of the working hotels in Amman city is measured by using the fifth liker measurement for testing the correlated and reasonable relations between the variables.

\subsection{The Measurement Tools}

The data and information are collected by analyzing the questionnaire according to the computer statistical program (SPSS).

The questionnaire was designing according to the fifth dimension liker measurement that explained the differences and gave the following:

Strongly agree_five grades

Agree _ four grades

Neutral_three grades

Disagree _tow grades

Strongly disagree_one grades

\subsection{Validity}

The instrument of the study is verified by being judged by a group of experienced and specialized jury in the administration and they were asked to modify the items of the questionnaire.

\subsection{Reliability}

To verify the reliability of the instrument Cronbach Alfa was used to limit the cohesion of the questionnaire items which was (93.65\%) that indicates a suitable reliability for the purpose of the study.

\subsection{Statistical Procedure}

The following statistical procedures used to describe the characteristics of the variables and the hypotheses testing:

Getting the percentage means and frequencies

Using the referent statistical methods to test the hypo the sis of the study to test the effect of the independent variables (the effect of the administration and components of the marketing knowledge) as the independent variable and the components of the competitive quality (distinguishing and responding as dependent variables).

Using sample line curve for calculate the values.

Using the multi only sis.

Calculating the value of (R2) and the multi correlation factor and the formal interpretation of probability.

Getting the cohesion of the items of the study of measure the instrument of the study.

\section{Related Studies}

Al seed and harem (2004) conducted a study aimed at identifying the relation between the knowledge administration information technology and the competitive quality for the organization in the medicine sector in 
Jordan from the perspective of the working managers in the medicine industrial companies.

The findings indicated that knowledge has become the most important resource of the modern organization.

In addition, the information is considered effective power ruling different life domains including the organization.

The recommended assured strengthening the awareness and perception of the people in charge and the workers in the great challenges and raiding faces in Jordan.

In addition, the necessity of caring about the administration of knowledge and information technology in such organization by creating an organizational writ program of administration knowledge and information technology connected directly with the highest authority in the company.

Al Bakery and Suleiman (2006) conducted another study about marketing knowledge managing and its reflection on the relation with the customer to achieve the competitive quality.

The study aims at assessing the extent of the relation between marketing knowledge managing and reinforcing the ability to achieve the competitive progress in the environment of the competitive organization.

The findings showed that the business organization worked at achieve variant quality in its ability mingle the marketing achieves in general organizational conceptual framework and join it with information technology to create a system for the marketing knowledge managing to make the organization capable of keeping its accumulative knowledge and building a thoughtful piling based on its competence and its dealing with the market variations.

In addition, the study indicated that the marketing knowledge managing processes would be an essential gate between the marketing skills and the relations with the customers to enable it to deal better with the non traditional environmental problems and use the marketing chances to survive with in the competitive frame and keep its competitive situation in the marketing

Al Fuqaha (2011) conducted another, study about the role of knowledge managing in achieve the competitive advantage. In the working assurance complaint in Naples city. Aims at identifying the role of, knowledge managing in achieving the competitive quality in the working assurance completive in Naples, city from the perspective of its employees.

It was clear that there was a competitive advantage due to the application of knowledge managing in the in the company.

There was also a role of the technological knowledge in achieving the competitive advantage, in addition to the role of marketing knowledge in all chances of delivering, organizational knowledge; the researcher recommended the necessity for developing the knowledge renew ally and dead with the accumulative acquired experiences.

Al sheikh and Al Faqhi (2011) conducted a study about the role of marketing, knowledge management in, backing up the business organization distinguishing and, the mechanism of its apical aims to find out the concept of marketing knowledge management and its relation with the customer and its, relation with the customer and identifying its practice reflection on the dusting wishing of the economic institutions. The findings indicated the exits importance of the, marketing knowledge management through applied practices The objective of the of the distinguishing is achieved through a comprehensive, marketing studying and analyzing for provided by the marketing knowledge management the offers an information Use for taking correct marketing decisions, in addition to having results that support managing, the business completive situation of the organizations.

Al Assail (2004) also conducted and there study aims to identify the knowledge to be, managed and its kinds, in addition to explain the processes and stages in order to know it's supposed role by the acquired demanded information and skills to be activated evicting, The study also focused on a particular category knowledge, that collets knowledge organizes and markets it available.

The specialists of dealing with all these things in knowledge management were focused on also and their new role and future vision in the age of knowledge management.

The descriptive, analytical method was applied in this study.

The findings showed that, the human resource is the basic element in age of knowledge management, whereas the technology has become the assistant tool, the continuity of competition.

Rebecca and Murray (1997) conducted a study aimed identifying the knowledge management by considering it a commercial activity seeks for generating knowledge for achieving competitive quality within the organization 
and connecting the information technology and computer system and their different developments with the process of getting, knowledge management and delivering it, as well, In addition itemed to identify the methods of knowledge, management by using technology in order to enhance the way of getting knowledge and reinforce the ways of using the data.

Goh Choon Yih, Gan, Pei Ling (2008) Knowledge Management Drivers for Organizational Competitive advantage, This paper aims to identify and examine key KM enablers in organizations, by reviewing related research and providing focused perspective on the relationship between developing these drivers and gaining competitive advantage in the market place. The study analyzes a set of KM drivers namely culture, structure, people, trust, and information systems (IS). The findings indicated that organizations would derive value from identifying specific aspects of the organization that may be developed to encourage effective knowledge management in the contemporary business landscape. As industry competition increase, organizations must develop functional strategies to gain and maintain an edge over rivals. Developing and leveraging on key KM drivers would enable organizations to achieve their performance objectives.

\section{Theoretical Background}

\subsection{The Concept of Marketing Knowledge Management}

Lloria (2008) identifies Knowledge management as Knowledge management would include information and knowledge-creating systems, as well as strategic management and innovation, Knowledge management is the processes that help the organization to generate information to be organized and to convert the important information and the pertinences that are necessary for the different administrative activities for decision making and problem solving (Alselmi, 2000) many writers that marketing knowledge concept appeared since the mid of the last century as it is represented the essence of marketing knowledge in transferring the focusing the attitude of business organization from focusing on work into focusing on the market and the matching of the accounts of such organizations with the expectations of the customers resulting being far away from inevitable failure in marketing their products, Therefore, marketing knowledge is defined as important basic essence in controlling the marketing works, in addition to being a subjective pivoted in structuring knowledge the successful marketing plans that on based on the wisdom of mind for measuring the different aviations of the market (Wright, 1998), it's also comprehensive for the collection of the concepts and activities that represent the marketing knowledge (Melhem, 2003).

The management of the relation with the customer represent the core of marketing knowledge, consequently, it densities the organization knowledge of their current, and probable customers through their shopping behaviors therefore, it will be in its strong position through its real interaction with the customers rather than theoretical framework in dealing with the customers behaviors (Hassan, 2007).

Marketing knowledge is identified by two main areas that include (Kotlar, 1999):

First: the concepts of marketing Knowledge management include

1) The philosophy of gearing the market by organizing planned activities according to the market demands.

2) Identifying the product position in the market by comparing the market product and its suitability with the customer's needs and the nature of the market.

3) Dividing the market into sectors to enable the organizations to conduct marketing studies.

4) The best use for the components of marketing mixture by finding a perfect formula to achieve the maximum benefit of four components of the marketing mixture.

5) Building up loyalty for the trade market through creating satisfaction for the customer by continuous dealing with the organization products.

6) Testing the market by not showing up the product in the market randomly but through presenting it in a limited market to gain primary results.

Second: Marketing activities including a collection of practices done by the business organization. These are:

1) Identifying the marketing objectives

2) Planning the marketing activities

3) Coordinating between the marketing activities

4) Provoking the customer and the workers

5) Assessing and supervising 


\section{6) Marketing research papers}

A number of marketing scientists dealt with the concept of marketing knowledge. Delbert and Smith (2002) stated that marketing knowledge management is considered as the institution resource through which the competitive quality is achieved and makes the application of marketing knowledge available, in addition to the focus on the organization usages to enhance and develop the process strategic marketing decision for the organization. Resister (2001) pointed out that there is an interference between the knowledge the job of marketing management and the strategy of the organization, general.

This has created thoughtful creations that found the cognitive development which is dealt with in to business strategies.

\subsection{Dimensions of the Marketing Knowledge}

Wright (1998) pointed out that marketing knowledge dimensions are the basic elements for the domains though which the marketing knowledge is consisted of those dimension are as follows:

1) content: it represents the distinguishing sides and the differences of what the organization owns of knowledge characteristics in the marketing domain, in addition to focusing on the information that is connected with the objectives to be achieved.

2) culture: it is considered the basic center for having the marketing knowledge, no marketing knowledge for the organization without having a culture enabling them to understand the distinguishing experiments in the marketing and creative practices which lead to transferring and managing the marketing knowledge.

In this respect Zelman (1991) discussed the problem of forming the marketing knowledge in some service organization.

He found that the most prominent obstacles that stop the organization to have a complete marketing knowledge is represented with the cultural part that is considered a weapon of tow edges in this case.

3) process: in the domain of the process that take place inside the organization there are stages should be activated to reinforce the marketing knowledge that the organization has.

Those stages are:

-Identifying the knowledge objectives through diagnosing the essence of knowledge of organization and limiting its future needs of knowledge.

-Knowledge distinguishing in the marketing part of the organization compared with the competitors.-

-Sustainability of marketing knowledge.

-Spreading out marketing knowledge.

-Using marketing knowledge

According to all what has been mentored, the researchers noticed that included some points for guidance to enable the organization to apply the concept of marketing knowledge therefore the suitable, the process of application demands understanding and welter to transfer and manage knowledge that leads to clarify the marketing activities that reinforce the marketing knowledge.

\subsection{Significance of Marketing Knowledge}

Marketing knowledge importance is originated from the following:

1) Expansion of marketing activities and is complications.

The markets have been expanded to international levels.

Therefore, the levels of knowledge about the characteristics and behaviors of the costumer and the divisions and the market characteristics demand the expansion of knowledge within the expansion marketing activities.

2) The short life cycle of the product which is a challenging for the decision markets. It reflects the necessity for having a wide marketing knowledge to minimize time in taking decisions in the process of developing the new products.

3) Increasing the demanded data and information to get limited profits. The decision markets to have a good decision in order, the ability of new and developed technology enable them to gain data, comprehend it and analyze it easily and effectively.

4) Management the marketing information helps the administration identify the customer, needs and desires 
through understanding their rapid needs and feed it.

5) Marketing information management works hard to know the reason of customers bad attitudes towards shopping and tries to bridge the gap between the customer expectations about the product or the service with what is really presented to them, in addition to know the performance of the mediators causing that negative attitudes of the customers.

6) Marketing information management identifies the size of the available resources in order to use it more effectively because through such information the profitable products and service could be identified and the non - needed ones could be discarded (Coakes \& Elane, 2003).

7) Globalizing economy wherever the information moves as it is transferred quickly as the light speed.

8) Increasing the competition among the organization, in addition to the increasing of creation and need discoveries and cringes Necessary Accelerating all domains to let such organization perceive that the management of information and creative processes is the means for survival in a strong competitive center under hard and rapidly changeable circumstances of work (Wiig, 2003).

\subsection{The Objectives of Marketing Knowledge Management}

The organizations should use its different capabilities to know the deep customers desires and then to focus needs that could be perceives in order to achieve a specific quality level that could not be achieved by other competitors. In addition, varying of the products to be able to adapt with the customer's needs and also able to quick respond with the development and changing of such needs, taste and arts of those customers otherwise, the offered product would be undesirable or even demanded by the customers (Malhorta, 1998). Enhancing the value perceived by the customer for presented products and services by the institutions, contribute in building up its completive quality. The organization competitive quality could be achieved if the customer realizes that what she gets of the highs value of the products and other services while dealing with the institution.

\subsection{Marketing Knowledge Management Aims to}

1) Make operations simpler and reduce costs by getting rid of lengthy procedures or unnecessary ones.

2) Enhance customer service by reducing required time to provide the services.

3) Adopt the idea of creativity by encouraging the ideas flowing principle in smooth and simple way.

4) Increase financial return through marketing products and services more effectively.

5) Activate knowledge and manage it in order to improve the methods of delivering products and services.

Marketing knowledge management includes:

\subsection{The Components of Marketing Knowledge}

\subsubsection{Market Knowledge}

According what researchers have written about the market knowledge, they reached to a specified and permanent definition to this popular term, however, most researchers in marketing field agreed that market knowledge including a set of concepts and activities which illustrate in total the required market knowledge. depending on the pioneers of this science and what they present about knowledge market's concepts and activities, with choosing agreed elements of the market concepts and activities among researchers,so we can summarize the meaning of market knowledge in seven concepts of and six activities (Akaah et al., 1988; Kotler, 1991; Mohamad et al., 1992; Pride \& Ferrell, 1985).

The Concepts of market knowledge:

1) Guidance in Market philosophy

2) Determine product status in the market

3) Divide the market into segments

4) Perfect exploitation of the marketing mix elements

5) Create the brand's loyalty

6) Product variation (differentiation)

7) Market test

The activities of market knowledge:

1) Determining the market goals 
2) Planning marketing activity

3) Coordination and integration between marketing activities

4) Motivation

5) Oversight and evaluation on marketing activity

6) Marketing Researches

\subsubsection{The Competition Knowledge}

Competitiveness is a skill, technique or outstanding supplier which allows organization to produce values and benefits to customers More than what is offered by their competitors, and confirms their excellence and difference from those of competitors as customer point of view Who accept this difference and excellence, which will achieve more benefits and values that are superior to what Is offered by their competitors (Al-sulmi, 2002).

The competitor from the organization's point of view "is any company shares in getting a part of the spent funds of Customers on the same kinds of products", so the success of any organization depends on the trust of customers and turn out to spend their money on our goods and services.

The importance of analyzing the surrounding competition:

Many organizations depend on its growth on attract customers from another competitors, so it requires from the organization management to determine which are the organizations that will be the object of attack them,

In particular, the organization must answer three important questions are where, when, and how they will attack.

The answer to each one of these questions constitutes a major component in the strategic marketing planning process for organization.

The objectives of surrounding competition analysis (Al-sawe, 2007)

1) The desire to encounter new entrants who want to offer the same product with better quality and Lower prices to get market share

2) The desire to encounter changing in customer wishes and their increasing desires with profit continue

3) Compare the defensive and attacked strategies which competitors use in the market

Major points of surrounding competition analysis and competitors:

1) Planning the suitable strategy to determine the strength points of each competition organization whenever it would be possible.

2) To identify the reasons and motives that make customers choose to deal exclusively with the organization without other competition organizations.

3) Help customers and enable them to develop real standards which they can through evaluate the services that offered by the organization positively compared with other competition organization's services.

\subsubsection{The Knowledge of Consumer Needs and Desires}

Information about consumers is available to every accurate detail of transaction and personal information. Information is aimless without suitable analytics. This information needs to be transformed into appropriate consumer knowledge to be used as and when necessary (Sternberg, 2005).

Knowledge of consumer needs and desires generally involve information dealing with "what customers say". Traditional market research methods such as (personal depth interviews, surveys, focus groups, e-questionnaires, and product clinics) can be used to collect data on articulated needs (Urban \& Hauser, 2004; McDonagh-Philp \& Bruseberg, 2000). Well-known market research methods include conjoint analysis, perceptual mapping, segmentation, preference modeling, and simulated test markets. Information on articulated needs can be obtained using category problem analysis (Tauber, 1975; Swaddling \& Zobel, 1996). Other techniques include repertory grids, Echo procedures, verbal protocols, laddering and means-ends analysis (Reynolds \& Gutman, 1988), as well as projective techniques like product personality profiling, having customers draw their ideal product, hypnosis, and archetype analysis (Shalit, 1999). Knowledge of consumer needs and desires leads to products that are desirable, feasible, and salable (to the mass market).

9.6.4 The Knowledge of Available Marketing Opportunities

Kottlar (2003) identified marketing opportunity as "the attractive area of company 's marketing that through it can get a competitive advantage". In order for any organization to analyze marketing opportunities, it should 
have a clear idea of its goals and potentials, as well there should be a full understanding of the surrounding environmental conditions, the market sectors and consumers.

Searching for marketing opportunities is not random, but accordance scientific methods and approaches in analyzing these opportunities, no doubt that modern organizations have the ability to identify the current and future opportunities in the market, but not every organization can be able to exploit it's available opportunities, maybe there are many reasons, including inability to exploit these opportunities in the suitable time due to lack of technological possibilities, material, financial or human ones, or may be the reason is the disagreement between these opportunities and their strategic objectives, or it depends on identifying their strength and weakness points to determine if there is possible to exploit them or not determine available marketing opportunities

The modern organizations can identify these opportunities through searching of marketing opportunities, this can be done in many ways, it can be done by accident and without follow the systematic methods by reaching to new ideas through follow-up changes in the markets and the surrounding environment (Ansoff, H. Igor; McDonell, Edward, 1990) for example, finding marketing opportunities through participation and attendance at trade fairs and study competitors' products or may be by information which arrives by marketing intelligence, or through finding new ideas.

Marketing opportunities do not exist automatically, but comes as a result of intensive and focused efforts from marketing management, these efforts part of the marketing department. Since all of the environmental and internal changes in the organization effect on the quality and quantity of available marketing opportunities, so it became necessary to have a comprehensive and integrated approach in order to identify new opportunities to serve all who deal with the organization itself.

The approach consists of several steps, they are:

Identify the effects of environmental and public impact

Assess the activity of competitors

Assess the available potentials of organization

Identify the targeted market segments

Determine the size of the demand in the targeted market segments

Select group from the targeted market

\section{The Competitive Advantage}

In recent years, subject of competitive advantage has attracted widespread attention at the global level. This is due to convoying the requirements of rapidly developments which take place in the world that present in the globalization phenomenon and merging in global economy, and the policies of openness and markets liberalization (Hoffman, 2000). In addition to the enormous developments in information and communication technology, and in light of these crucial developments, it is difficult for any country to live apart from these developments that because of difficulties and encumbrances which will face it, especially in export and capital flows fields, so the developing countries started to adopt a reforming policies that aim to rehabilitate and restrict Their economies and create a favorable economic environment that support their in a changing world economy (Mursi, 2007).

Competitive advantage Achieved through the better exploitation of the abilities, technical resources, material, financial, Regulatory and informatics, in addition to the qualifiers and other Institution abilities which make it able to design and apply its competitiveness strategy so to achieve competitive advantage it associated with main Two-dimensions: the response, and the organization's ability to achieve excellence.

\subsection{First Dimension: Response}

Algalibi (2009) pointed out that Organizations must exploit their different potentials in accurately identifying on customers at the first, then concentrate on the needs that can aware by getting a certain level of quality which is difficult to achieve by competitors, and to pay attention to Product mix Diversification to be able to adapt with customer's needs, and it should be able to Rapid response with the increasing of those needs and palates, otherwise the provided product become not required to Customers, improve the value which perceived by the customer for institution's provided goods and services, it contribute to building the competitive advantage, and achieve the competitive advantage of organizations if the client realize that what they get as a result of their dealings with the institution has a higher value than other products and services. 


\subsection{Second Dimension: Distinguishing Quality}

The competitive quality could also be achieved through showing up a product or service the other competitors could not imitate it easily or make a copy-base out of it. In fact, there are many resources through which reaching (Financial resources, human organizational and information resources).

\subsubsection{Financial Resources}

The institution could achieve being distinguished by getting funding for all its needs only to prices than others.

\subsubsection{Material Resources}

It includes the tools and technology, in addition to the capability of the institution to get the suitable support for the process of production. By using all such materials the product or service could be offered in a more different and distinguished way than other institution.

\subsubsection{Human Resource}

The success of many institutions is attributed basically for the skills and the human abilities it owns.

\subsubsection{Organizational Capabilities}

It is the ability of the institution to run its systems and available individuals inside it, to med its customers' needs. This resource contributes effectively in giving a value for the organization products or services that are seldom be imitated.

\subsubsection{Information and Information Technology}

It plays an important role in achieving distinguishing in the market and achieving the strategic objectives for the institution.

They also said (Sheikh \& Badr, 2004) that there are several methods which lead to achieve distinguish, including:

The Superior efficiency

It is related with the expenses of the suitable inputs for producing specific out puts or out comes leading to achieving surpass competence. In addition, the competitive strategy, the suitable organizational skeleton and the control systems the organization has contribute in achieving a high her competence compared with the competitors.

The Superior quality

The quality is measured through what the products and services achieve by being accepted by customers. The level of the performance of these products, services and the high quality helps in forming a trade mark brand of good reputation and decreasing effort and time that is used in reforming the defect of the product. The quality is not the decreasing of the defect of product, but it is a means for pleasing and satisfying the customers to make them to be more connected with the product.

\section{Creativity and superiority}

It is achieved through offering a new product or working in a new different way not a like other competitors.

\section{Objectives of the Competitive Advantage}

The organization work to achieve its objectives through the competitive advantage by doing the following:

1) Creating new marketing chances in the market like the mobile company.

2) Entering new markets or dealing with new people by having new competitive domain or new quality of products.

3) Forming a new vision for the future the organization is looking forward to.

4) Making allies relations with the importers which enable them to get the needs in easier ways, competence and less expenses.

\section{Hypotheses Test}

This paragraph contains the main and sub hypotheses test, through using of multiple and simple regression analysis:

The main hypotheses

There is no significant statistical effect for the marketing knowledge management ( knowledge of markets, 
Knowledge of customer's needs and desire, Knowledge of competition, Knowledge of the availability and marketing chances to achieve the competitive advantage for the working hotels in Amman according to (distinguishing, responding) at the statistical reference level $(0.05 \geq \alpha)$.

The first sub- hypothesis Ho1:

There is no significant statistical effect for the markets knowledge in achieving a competitive advantage (distinguishing responding) at the statistical reference level $(0.05 \geq \alpha)$.

Table 1. Linear regression testing between (markets knowledge) and competitive advantage from distinguish side

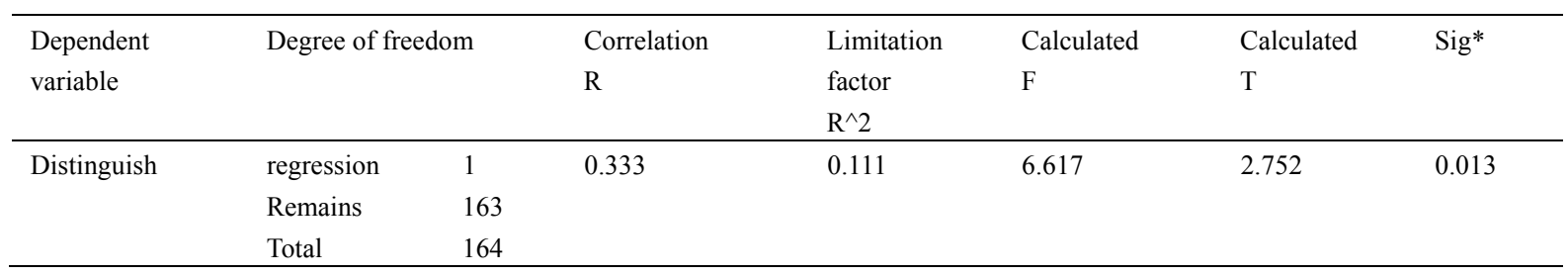

Table 1 shows that there is no significant statistical relation between the marketing knowledge in achieving the competitive advantage in Amman hotels at the stoical reference level $(0.05 \geq \alpha)$ which was $(0.013)$ whereas the correlation $(\mathrm{R})$ was $(0.013)$ at the statistical reference level $(0.05 \geq \alpha)$ the limitation factor $\left(\mathrm{R}^{\wedge} 2\right)$ was $(0.011)$ in a value of (0.111) from the changes in achieving the competitive advantage according to dusting weighing resulted from the changing in the level of the marketing knowledge level.As for calculated $F$ value it was (6.617) which is significantly statistical at the level $(0.05 \geq \alpha)$ which assures the effect.therefore the result of not accepting the $\mathrm{q}$ hypo the sis and the acceptance of the alternative hypothesis.

That implies (There is significant statistical effect for the knowledge in achieving a competitive advantage (distinguishing responding) at the statistical reference level $(0.05 \geq \alpha)$.

The second Sub- hypothesis $\mathrm{HO} 2$ :

There is no significant statistical effect for the knowledge of the customer's needs and desires in achieving a competitive advantage (distinguish, ) at the statistical reference level $(0.05 \geq \alpha)$.

Table 2. Linear regression testing between (knowledge of the customer's needs and desires) and competitive advantage from distinguish side

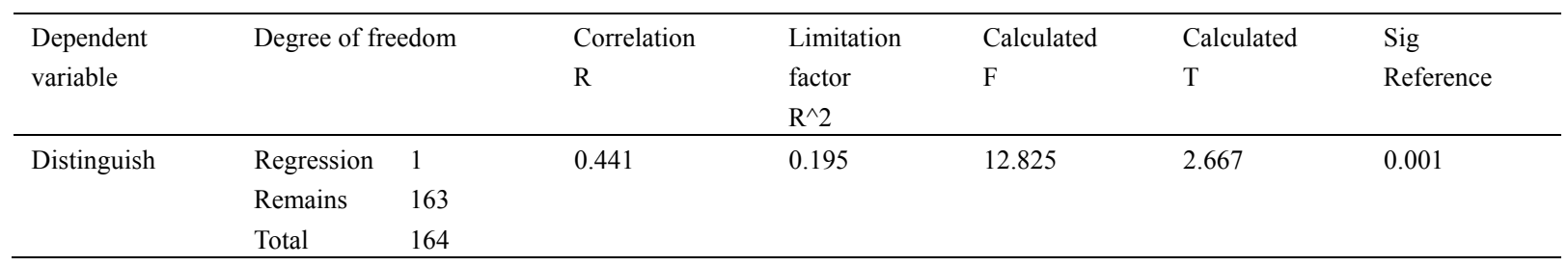

This clear from table 2 that there is significant statistical relation between the knowledge about the customer's needs in Amman hotels at the statistical reference level $(0.05 \geq \alpha)$ which was $(0.001)$ the correlation $(\mathrm{R})$ was $(0.441)$ at the level $(0.05 \geq \alpha)$ in a value of $(0.195)$ form the changes in aching the competitive advantage according in the level of knowledge about the customer's needs and desires the calculated value of (F) was (12.825) which is statistically significant at the level of $(0.05 \geq \alpha)$ which assures the effect there for the result is by refusing the null hypothesis and accepting the alternative one that there is a significant statistical effect for the knowledge about the custom's needs and desires in achieving completive advantage for the working hotels in Amman in accordance with (distinguishing) there is no statically significant effect for the completive knowledge for the working hotels in Amman according to (distinguish) at the statistical referee level $(0.05 \geq \alpha)$.

The third Sub- hypothesis HO3:

There is no significant statistical effect for the knowledge of competition in achieving the competitive advantage from Distinguish side at the statistical reference level $(0.05 \geq \alpha)$. 
Table 3. Linear regression testing between (knowledge of competition) and competitive advantage from distinguish side

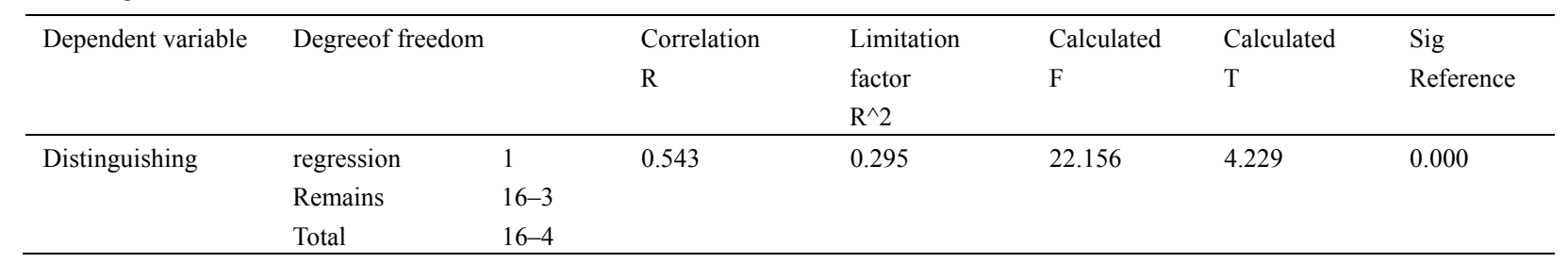

It is clear from Table 3 that there is significant statistical relation between knowledge of competition in achieving the competitive advantage in Amman hotels at the statistical reference level $(0.05 \geq \alpha)$ which was $(0.000)$ the correlation $(\mathrm{R})$ was $(0.543)$ at the level $(0.05 \geq \alpha)$ of $(0.295)$ of the changes in achieving the competitive quality according to dieting wishing resulting from the change of the competitive knowledge level. The value of $(\mathrm{F})$ was (22.156) which is statistically significant at the level $(0.05 \geq \alpha)$ which assures the effect therefore the result is refusing the null hypothesis and accepting the alternative one which implies (there is a significant statically) reference for the competitive knowledge in achieving competitive advantage the working hotels in Amman according to (Distinguishing) there is also a significant statistical effect for the knowledge of the available marketing chance in achieving competitive advantage for the working hotels in Amman in accordance with (Distinguishing at the level $(0.05 \geq \alpha)$.

The fourth Sub- hypothesis HO4:

There is no significant statistical effect for the knowledge of the availability marketing opportunities in achieving the competitive advantage from Distinguish side at the statistical reference level $(0.05 \geq \alpha)$.

Table 4. Linear regression testing between (the knowledge of the availability marketing opportunities) and competitive advantage from distinguish side

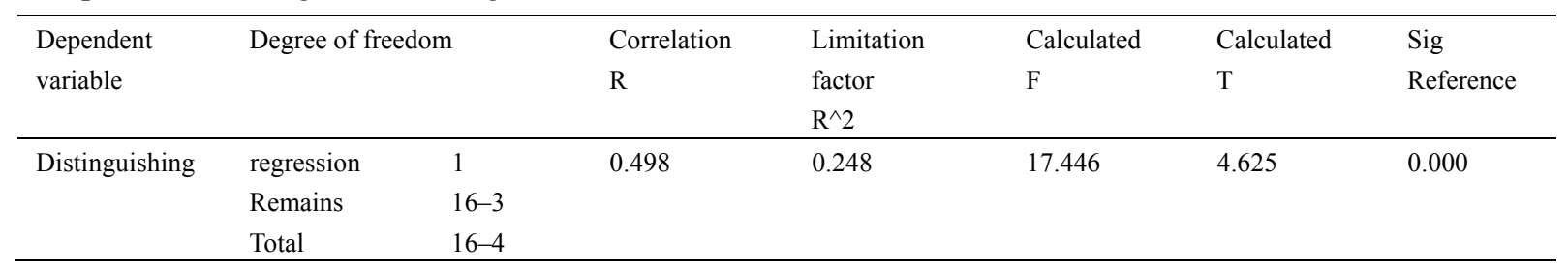

It is clear table (4) that there is a significant statistical relation between the knowledge of the availability marketing opportunities in achieving the competitive advantage in Amman hotels at the statistical reference level $(0.05 \geq \alpha)$ which was $(0.000)$. The correlation value $(R)$ was $(0.498)$ at the level $(0.05 \geq \alpha)$ whereas $(0.248)$ from the changes in the level of the competitive advantage knowledge accreting to dieting wishing restating from the change in the level of the knowledge of the available marketing chances. The calculated value of (F) was (17.446) which is statistically significant at the level $(0.05 \geq \alpha)$ which assures this effect therefore the result is by refusing the null hypothesis and accepting the alternative one that implies (There is significant statistical effect for the knowledge of the availability marketing opportunities in achieving the competitive advantage from Distinguish side at the statistical reference level $(0.05 \geq \alpha)$.

The five sub- hypothesis Ho5:

There is no significant statistical effect for the knowledge in achieving a competitive advantage from responding side at the statistical reference level $(0.05 \geq \alpha)$. 
Table 5. Linear regression testing between (markets knowledge) and competitive advantage from responding side

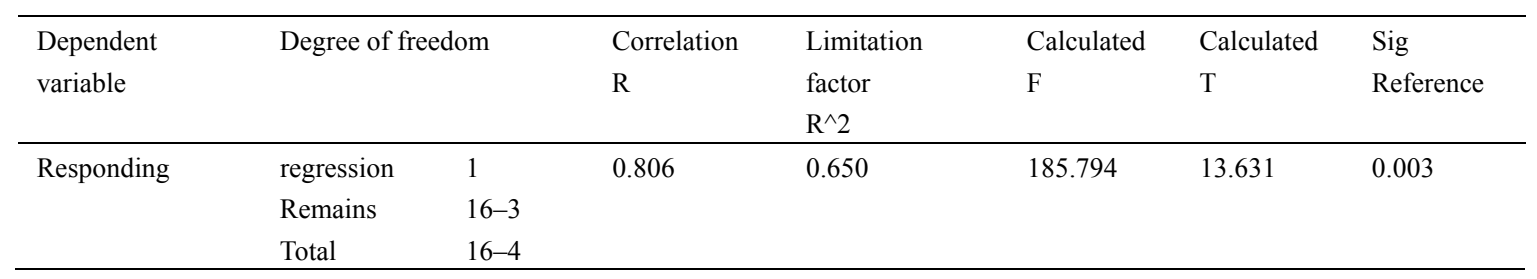

It is Clear from Table 5 that there is a significant statistical relation between markets knowledge in achieving the competitive advantage in Amman hotels at the statistical reference level $(0.05 \geq \alpha)$. which was $(0.003)$ the correlation value $(R)$ was $(0.806)$ at the level $(0.05 \geq \alpha)$. the value of $\left(R^{\wedge} 2\right)$ was $(0.650)$ in a value of $(0.650)$ from the changes in achieving the competitive advantage according to responding resulting from the change in the level of marketing knowledge the which statistically significant at the level $(0.05 \geq \alpha)$ which a sure the effect therefore the result is in refusing the null hypothesis and accepting the alternative one that implies (There is significant statistical effect for the knowledge in achieving a competitive advantage from responding side at the statistical reference level $(0.05 \geq \alpha)$.

The six Sub- hypothesis HO6:

There is no significant statistical effect for the knowledge of the customer's needs and desires in achieving a competitive advantage responding side at the statistical reference level $(0.05 \geq \alpha)$.

Table 6. Linear regression testing between (the knowledge of the customer's needs and desires) and competitive advantage from responding side

\begin{tabular}{|c|c|c|c|c|c|c|c|}
\hline \multirow{2}{*}{$\begin{array}{l}\text { Dependent } \\
\text { variable }\end{array}$} & \multicolumn{2}{|c|}{ Degree of freedom } & \multirow{2}{*}{$\begin{array}{l}\text { Correlation } \\
\mathrm{R}\end{array}$} & \multirow{2}{*}{$\begin{array}{l}\text { Limitation } \\
\text { factor } \\
\mathrm{R}^{\wedge} 2 \\
\end{array}$} & \multirow{2}{*}{$\begin{array}{l}\text { Calculated } \\
\text { F }\end{array}$} & \multirow{2}{*}{$\begin{array}{l}\text { Calculated } \\
\mathrm{T}\end{array}$} & \multirow{2}{*}{$\begin{array}{l}\text { Sig } \\
\text { Reference }\end{array}$} \\
\hline & & & & & & & \\
\hline \multirow[t]{3}{*}{ Responding } & regression & 1 & 0.433 & 0.170 & 129.322 & 11.718 & 0.021 \\
\hline & Remains & $16-3$ & & & & & \\
\hline & Total & $16-4$ & & & & & \\
\hline
\end{tabular}

It is clear from table 6 that there's a significant statistical relation the knowledge of the customer's needs and desires in achieving the competitive advantage in Amman hotels at the level $(0.05 \geq \alpha)$ which was $(0.021)$ the correlation value was $(0.433)$ at the level $(0.05 \geq \alpha)$ the value $\left(R^{\wedge} 2\right)$ was $(0.170)$ in a value of $(0.170)$ from the changes in achieving the competitive advantage in accordance with responding resulting from the change in the level of the knowledge of the customer's needs level $(0.05 \geq \alpha)$ which assures the effect therefore the result is refusing the null hypothesis and accepting the alternative one implies (There is significant statistical effect for the knowledge of the customer's needs and desires in achieving a competitive advantage responding side at the statistical reference level $(0.05 \geq \alpha)$

The seven Sub-hypothesis HO7:

There is no significant statistical effect for the knowledge of competition in achieving the competitive advantage from responding side at the statistical reference level $(0.05 \geq \alpha)$.

Table 7. Linear regression testing between (knowledge of competition) and competitive advantage from responding side

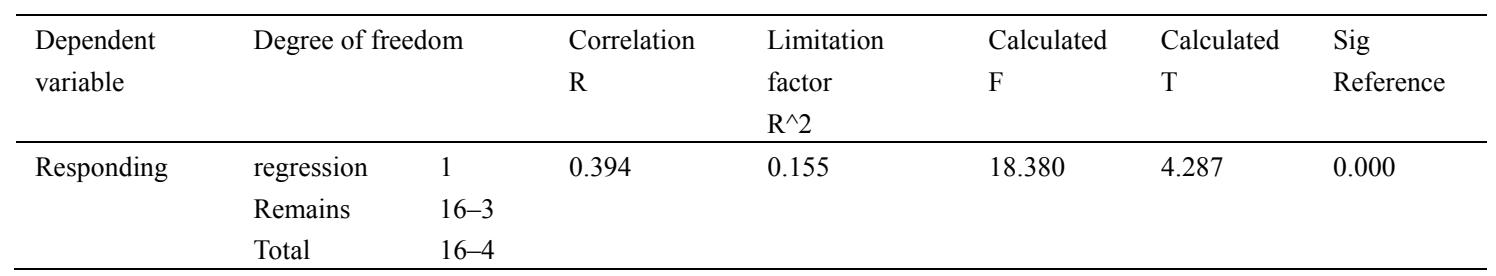


It is clear from table 7 that there is a significant statistical relation between competitive knowledge in achieving the competitive advantage in Amman hotels at the level $(0.05 \geq \alpha)$ which was $(0.000)$ the correlation value (R) was $(0.394)$ at the level $(0.05 \geq \alpha)$ the value of the changes in achieving the competitive advantage in accordance with responding resulting from the change the level of competitive which is statistically significant $(0.05 \geq \alpha)$ which assures the effect therefore the result is in refusing the null hypothesis and accepting the alternative one that implies there is significant statistical effect for the knowledge of competition in achieving the competitive advantage from responding side at the statistical reference level $(0.05 \geq \alpha)$.

The eight Sub- hypothesis HO8:

There is no significant statistical effect for the knowledge of the availability marketing opportunities in achieving the competitive advantage from responding side at the statistical reference level $(0.05 \geq \alpha)$.

Table 8. Linear regression testing between (knowledge of the availability marketing opportunities) and competitive advantage from responding side

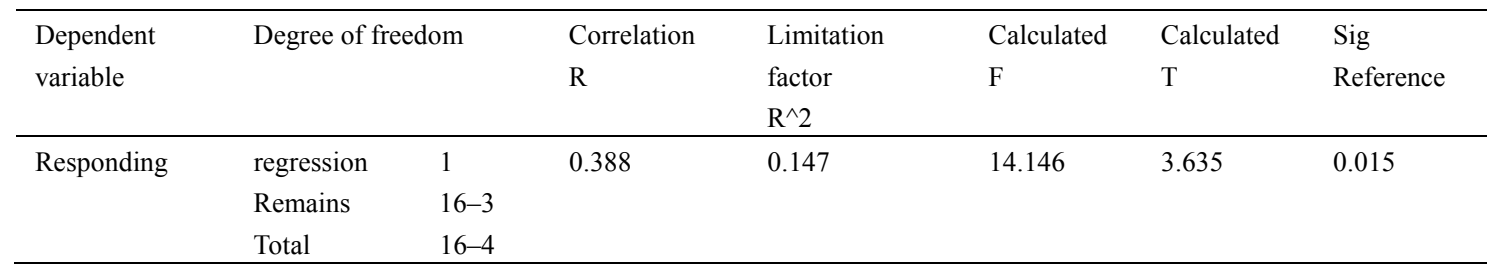

It is clear form table 8 that there is a significant statistical relation between the knowledge of the available marketing chances in achieving the competitive quality in the working hotels in Amman at the statistical reference level $(0.05 \geq \alpha)$ which was $(0.015)$. The correlation value $(\mathrm{R})$ was $(0.388)$ at the level $(0.05 \geq \alpha)$ the value of $\left(R^{\wedge} 2\right)$ was $(0.147)$ in a value of $(0.147)$ from the changes achieving the competitive quality in accordance of responding resulting from the change in the level of the knowledge in the available marketing opportunities the calculated value of (F) was (14.146) which is statistically significant at the statistical reference level $(0.05 \geq \alpha)$ which assures the effect therefore the result is in refusing the null hypothesis and accepting the alternative one that implies (There is no significant statistical effect for the knowledge of the availability marketing opportunities in achieving the competitive advantage from responding side at the statistical reference level $(0.05 \geq \alpha)$.

\section{Findings}

The participants' answers agree with all the items that measure the variable of marketing knowledge in medium and high degrees the items that implies "the hotels estimates" the selling power in different selling areas in the market was the last concern for the participants.

The participants answers agree with all items that measure the variable of the knowledge of the customer's needs and desires in medium and high degrees. The item that implies the hotel depends on marketing information system to know the customer's needs and desires got the least concern of the participants.

The participants answers agree with all the items that measure the variable of the knowledge about competition in medium and high degrees the item that implies the hotel trains the individuals and the worker to make specific accurate questions about the competitors to be a reference for marketing decision marking was the last concern for the participants.

The participant's answers the variable of the knowledge about the available marketing chances in medium and high degrees the items that implies the hotels works on decision marketing and conducing for identifying the available marketing chances in the market got the least concern of the participants.

The attitudes of the participants answers were in agreement with all the items that measure the competitive quality about distinguishing in medium and high degrees the item that implies the hotel seeks for gaining in formational certificates and rewards in distinguishing domain about hotel service quality took the least concern of the participants.

It is clear that there is a significant statistical reference between the knowledge about the customer's needs and desires to achieve the competitive quality in the working hotels in Amman the statistical reference level was $(0.021)$ whereas the correlation $(R)$ was $(0.433)$ the $\left(R^{\wedge} 2\right)$ was $(0.170)$ in a value of $(0.170)$ of the changes in achieving the competitive quality according responding domain result from the changing in the knowledge level 
about the customer's needs and desires.

There is a significant statistical reference between the knowledge about the competition in achieving the competitive quality in the working hotels in Amman the statistical reference level was (0.000). The correlation (R) was $(0.394)$ where as the $\left(\mathrm{R}^{\wedge} 2\right)$ was in a value of $(0.155)$ of the changes in achieving the competitive quality according to responding resulting from the changing of the competition knowledge level.

There is a significant statistical reference between knowledge of the available marketing chances in achieving the competitive quality in the working hotels in Amman the statistical reference level was $(0.015)$ the correlation (R) was $\left(0.388\right.$ and $\left(\mathrm{R}^{\wedge} 2\right)$ was $(0.147)$ in a value of $(0.147)$ about the changes in achieving to responding domain resulting from the knowledge level about the available marketing chances.

\section{Conclusion}

This study conceived the importance of the marketing knowledge management for those who work in the hotel industry in Jordan, and its role in achieving a sustainable competitive advantage which make these hotels are able to continue in market and achieve customer satisfaction by meeting their needs and expectations with what they actually offer to them, Although there were some limitations for this study, which illustrated by lack of hotel workers cooperation with researchers, the tight of chronological element, in addition the individual differences among respondents in the understanding and awareness of the questionnaire's content, and the tendency possibility from some respondents to the ideal in their answers, which reflect that their choices are contrary to reality because they believe that straightforward answers can be subjected to criticism. But the study came out the results may be useful for the managements which working in hotels in Jordan besides a number of suggestions which are: need to seek operating hotels in Jordan towards the development of their existing marketing knowledge through knowing the details of the current competition reality, market variables and the reasons which make purchasing decisions for hotel customers and what enable them to sustain their existing competitive advantages, in order to achieve the above objective Hotels should transforme the modern scientific concepts, including marketing concepts, to activities and daily practices in line with its potentials.

\section{References}

Akaah, I. P. (1988). Applicability of Marketing and Management Activities in the Third World: An Empirical $\begin{array}{lllll}\text { Investigation. Journal of } & \text { Business }\end{array}$ http://dx.doi.org/10.1016/0148-2963(88)90038-0

Al magribi \& Abdel-Hamid, A. F. (2002). Management Information Systems. Modern Library for printing and distribution, Mansoura University.

Al saed, Mohammed, R., Harem, \& Hussein, M. (2004). The relationship of knowledge management and information technology and the competitive advantage of the organization (field study, on the industry sector). Jordan Journal, 8(1).

Alsellmi, A. (2000). Knowledge management. Cairo, Dar Quba for printing and publishing.

Coakes, E. (2003). Knowledge Management Current Issues and Challenges. Group publishing, U.S.A. http://dx.doi.org/10.4018/978-1-931777-51-3

Delbaere, M., \& Smith, M. C. (2002). Knowledge and Persuasion: Applying Marketing Models to Knowledge Management. Aspen school of business, University of manitoba, Canada.

Ghalibi, T., \& Idris, S. (2009). Strategic Management: A Perspective Systematically Integrated (2nd ed.). Wael for Publishing and Distribution, Amman, Jordan.

Goh, C. Y., \& Gan, P. L. (2008). Knowledge Management Drivers for Organizational Competitive Advantage. Proceedings of Applied International Business Conference.

Hassan, H. A. (2008). Knowledge Management Strategies in Business Organizations. Dar ethra'a for publication and distribution, Jordan.

Hunt, S. D., \& Robert, M. M. (1995). The Comparative Advantage Theory of Competition. Journal of Marketing, 59. http://dx.doi.org/10.2307/1252069

Kotler, P. (1991). Marketing Management Analysis, Planning, implementation, and Control (7th ed.). Englewood Cliffs, N.J.: Prentics-Hall, Inc.

Lloria, M. B. (2008). A review of the main approaches to knowledge management. London.

Malcolm, W. (1998). Progress in Marketing Knowledge. Journal of Empirical Generalizations in Marketing 
Science, 3 .

Malhorta, Y. (1998). Knowledge Management: Knowledge Management and Workers, a View from a Front Line.

McDonagh, P. D., \& Bruseberg, A. (2000). Using Focus Groups to Support New Product Development. Engineering Designer, 26(5), 4-9.

Melhem, S. A. (2003). The possibility of the adoption and the application of modern marketing knowledge and its impact on the performance of the industrial sector in Saudi Arabia. Second Arab Forum for marketing in the Arab world, the opportunities and challenges, Doha, Qatar.

Mohamed, O., Akaah, I. P., \& Riordan, E. A. (1992). Marketing Management and Mix Activities of Malaysian Manufacturing Firms. Journal of Malaysian Studies, 10(2), 49-71.

Mursi, J. D., \& Bakr, A. (2007). Strategic thinking and strategic management, curriculum application. University House for publication and distribution, Cairo, Egypt.

Nicole, P. H. (2000). An examination of the Sustainable Competitive Advantage. Academy of Marketing Science Review.

Pride, W. M., \& Ferrell, O. C. (1985). Marketing Basic Concepts and Decision (2nd ed.). Houghton Miffin, Boston, Mass.

Reynolds, T., \& Gutman, J. (1988). Laddering Theory, Method, Analysis, and Interpretation. Journal of Advertising Research, 28, 11-31.

Rossiter, J. R. (2001). What is marketing knowledge? Marketing Theory Articles, 1, 9-26. http://dx.doi.org/10.1177/147059310100100101

Sawi, Y. (2007). Knowledge management and information technology. Cairo, Dar Al-Sahab for publication and distribution.

Shalit, R. (1999). The Return of the Hidden Persuaders. Salon Media. Retrieved from http://www.salon.com/media/col/shal/1999/09/27/persuaders

Sheikh, F. N., \& Badr, M. F. (2004). The relationship between information systems and competitive advantage in Jordanian pharmaceutical sector. Journal of Public Administration, 44.

Sternberg, R. J. (2005). Successful theory of Intelligence. Journal of Psychology, 39(2), 189-202.

Swaddling, J., \& Zobel, M. (1996). Beating the Odds. Marketing Management, 4(4), 20-33.

Tauber, E. (1975). Discovering New Product Opportunities with Problem Inventory Analysis. Journal of Marketing, 39(Jan.), 67-70. http://dx.doi.org/10.2307/1250805

Urban, G., \& Hauser, J. (2004). Listening In to Find and Explore New Combinations of Customer Needs. Journal of Marketing, 68(April), 72-87. http://dx.doi.org/10.1509/jmkg.68.2.72.27793

Wiig, K. (2003). Knowledge Management Foundations: Thinking. Arlington: Schema Press.

Wright, M., \& Kearss, Z. (1998). Progress in marketing knowledge. Journal of Generalizations in Marketing Science, 3, 1-16.

Zaltman, P. C. (1991). Foreign Enterprises and Marketing Know-How.

\section{Copyrights}

Copyright for this article is retained by the author(s), with first publication rights granted to the journal.

This is an open-access article distributed under the terms and conditions of the Creative Commons Attribution license (http://creativecommons.org/licenses/by/3.0/). 